\title{
Factores de Crecimiento Incluidos en Terminologia Embryologica: Análisis Crítico
}

\author{
Growth Factors Included in Terminologia Embryologica: Critical Analysis
}

Daniel Conei ${ }^{1,2,3} \&$ Mariana Rojas ${ }^{2}$

CONEI, D. \& ROJAS, M. Factores de crecimiento incluidos en Terminologia Embryologica: Análisis crítico. Int. J. Morphol., 36(2):500506, 2018.

RESUMEN: Cada término incluido en Terminologia Embryologica (TE), publicada en 2013 y con una segunda edicición en 2017 sujeta a aprobación por la Federación Internacional de Programas de Terminología Anatómica (FIPAT), se debe estructurar en base a sus principios: los nombres deben tener un valor informativo, se suprimen los epónimos, homónimos y nombres concordantes. Sin embargo, esto no ocurre en algunos términos. Es por ello que se analizaron los términos incluidos en el ítem "Factores de Crecimiento" (Factores crescentiae, E.4.0.1.0.0.0.1) en la forma en que se presentan, se contrastó su concordancia con lo publicado en revisiones de la base de datos PubMed y se describió la forma de nomenclatura de ellos en base a lo utilizado por el Comité de Nomenclatura de Genes de la Organización del Genoma Humano (HGNC). Se evidenció que en los términos Familia Hedgehog (Familia erinacea, E.4.0.1.0.0.0.6) y Superfamilia del Factor de Crecimiento Epidermal (EGF) (Superfamilia factoris epidermalis [EGF] crescentiae, E.4.0.1.0.0.0.10) no concuerdan con la clasificación propuesta por $T E$ en base al receptor que se ve involucrado en la actividad del factor de crecimiento, ya que en el caso de la familia Hedgehog no sólo participa el receptor patched, sino también el smoothened. En el EGF hay actividad del receptor tirosina kinasa y no del serina/treonina kinasa, como se presenta en el documento oficial. También, aparecen los ligandos fibronectina/laminina y delta/serrate como factores de crecimiento, pese a no ser catalogados como tal. Por otra parte, la forma en la que se construyen este tipo de términos muchas veces no es como la plantea la FIPAT, sino que obedece a la línea de trabajo que del HGNC. $T E$ debiese modificar el criterio empleado en el ítem factores de crecimiento.

PALABRAS CLAVE: Terminologia Embryologica; Factor de Crecimiento; Familia Hedgehog; Superfamilia de Factor de Crecimiento Epidermal; Ligando; HUGO Gene Nomenclature Committee.

\section{INTRODUCCIÓN}

Dado al acelerado avance del conocimiento científico, en todas las áreas de la ciencia existe la necesidad de utilizar un lenguaje común a nivel internacional. En este sentido, la morfología no se ha quedado atrás. Esto comenzó a finales del siglo XIX, cuando los anatomistas iniciaron una revisión de los términos usados hasta ese entonces en 1887 en Leipzig. Posteriormente, se realizó otra reunión en Londres en 1894, para que finalmente en 1895 en Basilea surgiera el listado términos de uso oficial en el área: La Nómina Anatómica de Basilea. Este precedente marcó un hito y transformó la enseñanza de la anatomía, agregando un objetivo más a sus fines: usar un lenguaje común y universal (Vásquez \& del Sol, 2014).

Con el paso del tiempo, este objetivo se extrapoló a otras áreas de la morfología, como lo son la histología y embriología. En el caso de la embriología, en poco más de 8 décadas después del primer intento realizado con la anatomía, se publicaron en forma conjunta la cuarta edición de la Nómina Anatómica y las primeras ediciones de la Nómina Histológica y la Nómina Embriológica, en 1977, siendo el primer paso para continuar trabajando y cuestionando los términos utilizados en embriología. Posteriormente, en 1980 se realizaron algunas sugerencias a cada una de las nóminas en el XI Congreso Internacional de Anatomía realizado en Ciudad de México, siendo publicadas en la segunda edición de la Nómina Embriológica. En 1989 se publica la tercera edición de la Nómina Embriológica. Sin embargo, esta no contaba con la revisión de la Federación Internacional de Asociaciones de Anatomistas (IFAA), ni con la aprobación del XIII Congreso Internacional de Anatomía que fue realizado en Río de Janeiro. Esto motivó a la IFAA a la creación

\footnotetext{
${ }^{1}$ Programa de Doctorado en Ciencias Morfológicas, Universidad de La Frontera, Temuco, Chile.

${ }^{2}$ Laboratorio de Embriología Comparada, Programa de Anatomía y Biología del Desarrollo, Instituto de Ciencias Biomédicas, Facultad de Medicina, Universidad de Chile, Santiago, Chile.

${ }^{3}$ Departamento de Ciencias Morfológicas, Facultad de Ciencia, Universidad San Sebastián, Puerto Montt, Chile.
} 
del Comité Federativo en Terminología Anatómica (FCAT), el cual posteriormente pasó a denominarse Comité Federativo Internacional en Terminología Anatómica (FICAT). Hoy en día es un organismo que trabaja en forma conjunta con la IFAA, llamándose Federación Internacional de Programas de Terminología Anatómica (FIPAT), cuyo objetivo principal es "Presentar la terminología oficial de las Ciencias Anatómicas, previa consulta a todos los miembros de la Federación Internacional de Asociaciones de Anatomistas, garantizando así una contribución democrática a la terminología". Actualmente, la FIPAT se encuentra trabajando en diversas áreas de la morfología, estando en revisión o construcción las Terminologías Anatómica, Histológica, Embriológica, Antropológica, Odontológica y Neuroanatómica (FIPAT, 2010).

En el caso de la Terminología Embriológica, la FIPAT comenzó su trabajo en el año 2008, siendo publicado y de libre acceso el borrador creado en el año 2009 (FIPAT, 2009). Se publica la primera edición oficial de Terminologia Embryologica (TE) en abril de 2013 (Thieme, Stuttgart, Alemania, ISBN 978-3-13-170141-1; eISBN 978-3-13-1701510). En febrero de 2017, se publica en versión digital la segunda edición, la cual se encuentra pendiente de aprobación por la Asamblea General en el próximo Congreso de la IFAA. Acá se incluyen nuevos términos en las áreas de desarrollo normal, anomalías congénitas y variaciones del crecimiento relacionados a neurociencias, células madre y fertilización in vitro (FIPAT, 2017). En ambas terminologías se agrupan todos los términos que tienen relación con la fecundación, gestación y nacimiento en el ser humano, cubriendo toda la ontogenia intrauterina hasta algunas características del desarrollo postnatal. Se divide en los siguientes capítulos: Nómina general (Nomina generalia), Ontogenia (Ontogenesis), Embriogénesis (Embryogenesis), Histogénesis general (Histogenesis generalis), Organogénesis (Organogenesis), Anexos embrionarios y fetales (Adnexa embryonica et fetalia), Estadios del desarrollo (Notatio temporum ontologicorum) y Nómina dismórfica (Nomina dysmorphica).

Por lo general, la disposición de los términos sigue la secuencia del desarrollo en forma cronológica y en base a los estadios de Carnegie. A diferencia de las otras terminologías, ésta no sólo se remite a estructuras, sino que también incluye procesos biológicos que son claves en el desarrollo pre y postnatal. Cada término se presenta en tres columnas: un identificador único, emparejado con la versión latina e inglesa del término. También, cabe destacar que $T E$ declara que el uso del latín como término principal proporciona un "Punto de referencia inequívoco, del cual cada lengua puede derivar su propio equivalente" (Losardo et al., 2015).
Para la construcción de cada término se deben considerar cuatro principios básicos: los nombres de las estructuras deben tener un valor informativo; se suprime los epónimos debido a que los nombres propios varían entre países; se suprimen los homónimos para evitar confusiones; y las estructuras en las mismas regiones anatómicas deben tener nombres armonizados (Latarjet \& Ruiz Liard, 2004). Pese a ello, hay ciertos términos incluidos en $T E$ cuya construcción no obedece a estos principios, como es el caso de aquellos que se clasifican como Factores crescentiae (E4.0.1.0.0.0.1) o factores de crecimiento. Es por ello que el objetivo del presente trabajo fue analizar los términos de este ítem en cuanto a la forma en la cual se realiza su nomenclatura y presentación, a fin de determinar si es compatible con la construcción propuesta por $T E$ y concordante con los hallazgos científicos descritos.

\section{MATERIAL Y MÉTODO}

Se evaluaron y analizaron los términos en Terminologia Embryologica publicada y aprobada en el año 2013 por la FIPAT que estuviesen incluidos en el ítem Factores crescentiae (E4.0.1.0.0.0.1), con el fin de determinar cuáles son los que se recomiendan usar y cómo es la organización y forma de presentación de los términos. Para dar el contexto histórico y funcional de ciertos términos incluidos en el ítem que causan conflictos en términos de la organización y estructura esquemática presentada por $T E$, se utilizó la base de datos PubMed buscando revisiones en donde se hiciera alusión al término en particular. Se utilizó la base de datos perteneciente a la HUGO Human Genome Organisation (HUGO) y el Gene Nomenclature Committee (HGNC) de la misma organización para ahondar sobre las directrices que guían la nomenclatura de genes y proteínas en la especie humana (HUGO Gene Nomenclature Committee, 2017).

\section{RESULTADOS}

Los términos que contempla $T E$ en el ítem Factores de crecimiento (Factores crescentiae) se encuentran en la Tabla I. La organización de los términos incluidos se encuentra de la siguiente forma:

En primer lugar, se nombra el receptor que es activado en la vía de señalización del factor de crecimiento en específico, siendo receptor tirosina kinasa (Receptor tyrosinum kinasis), receptor patched (Receptor maculatus), receptor frizzled (Receptor crispatus), receptor serina/ 


\begin{tabular}{lcc}
\hline E.4.0.1.0.0.0.1 & Factores crescentiae 89 & Growth factors \\
E.4.0.1.0.0.0.2 & Receptor tyrosinum kinasis & Receptor tyrosine kinase \\
E.4.0.1.0.0.0.3 & Familia factoris crescentiae fibroblasticae & Fibroblast growth factor [FGF] family \\
E.4.0.1.0.0.0.4 & Familia ephrini & Ephrin family \\
E.4.0.1.0.0.0.5 & Receptor maculatus & Receptor patched \\
E.4.0.1.0.0.0.6 & Familia erinacea & Hedgehog family \\
E.4.0.1.0.0.0.7 & Receptor crispatus & Receptor frizzled \\
E.4.0.1.0.0.0.8 & Familia receptoris non alati & Wingless-type [WNT] family \\
E.4.0.1.0.0.0.9 & Receptor serini/threonini kinasis & Receptor serine/threonine kinase \\
E.4.0.1.0.0.0.10 & Superfamilia factoris epidermalis [EGF] & Epidermal growth factor [EGF] superfamily \\
E.4.0.1.0.0.0.11 & Superfamilia factoris transformantis crescentiam $\beta$ & Transformin growth factor beta [TGF- $\beta$ ] superfamily \\
E.4.0.1.0.0.0.12 & Familia activini & Activin family \\
E.4.0.1.0.0.0.13 & Familia factoris morphogenetici ossium & Bone morphogenetic factor [BMP] family \\
E.4.0.1.0.0.0.14 & Familia factoris transformantis crescentiam & Transforming growth factor [TGF] family \\
E.4.0.1.0.0.0.15 & Factor transformans crescentiam $\alpha$ & Transforming growth factor [TGF- $\alpha$ ] \\
E.4.0.1.0.0.0.16 & Familia vitellogenini 1 & Vitellogenin [V g1] family \\
E.4.0.1.0.0.0.17 & Familia nodalis & Nodal family \\
E.4.0.1.0.0.0.18 & Receptor integrini & Integrin receptor \\
E.4.0.1.0.0.0.19 & Ligantia fibronectinillaminini & Fibronectin/Laminin ligands \\
E.4.0.1.0.0.0.20 & Receptor incisurans & Notch receptor \\
E.4.0.1.0.0.0.21 & Ligantia delta/serrata & Delta/Serrate ligands \\
\hline
\end{tabular}

Tabla 1. Ítem "Factores de Crecimiento" incluidos en Terminologia Embryologica. Thieme, Stuttgart, Alemania, 2013, ISBN 978-3-13170141-1; elSBN 978-3-13-170151-0.

treonina kinasa (Receptor serini/threonini kinasis), receptor integrina (Receptor integrini) y receptor notch (Receptor incisurans).

En segundo lugar, se nombran las superfamilias o familias de los factores de crecimiento, tales como la Familia de los Factores de Crecimiento Fibroblástico (FGF, Familia factoris crescentiae fibroblasticae), Familia de las Efrinas (Familia ephrini), Familia Hedgehog (Familia erinacea), Superfamilia de Factores de Crecimiento Epidermal (EGF, Superfamilia factoris epidermalis crescentiae), Superfamilia de Factores de Crecimiento Transformante $\beta$ (TGF- $\beta$, Superfamilia factoris transformantis crescentiam $\beta$ ), entre otros.

También, TE hace una especificación en torno a esta temática en un apartado a pie de página, en donde dice: "Los factores enumerados aquí son sólo representativos, pero se sabe que todos son activados durante la embriogénesis normal y en anomalías congénitas específicas, menos uno de ellos (TFG- $\alpha$ ). Es discutible si debe incluirse este criterio o no. El número de factores de crecimiento y sus familias continua en aumento dado el incremento del conocimiento en esta área" (FIPAT, 2013).

Una de las familias de factores de crecimiento incluidas es la Familia Hedtgehog (Familia erinacea), la cual se encuentra subordinada al receptor patched (Receptor maculatus). Esta familia corresponde a una serie de proteí- nas cuya vía de señalización en la etapa embrionaria produce una correcta diferenciación celular. Estas células embrionarias responden a diferentes concentraciones de proteínas de la señalización hedgehog (Li \& Dong, 2016). Esta familia lleva el nombre de su polipéptido ligando, una molécula de señalización intercelular llamada Hedgehog (Hh) que se encuentra en las moscas de la fruta del género Drosophila y en erizos de tierra. Hh es un gen de polaridad que participa en el establecimiento de la estructura corporal. La molécula sigue siendo importante durante las etapas posteriores de la embriogénesis y la metamorfosis (Wang et al., 2017). Los mamíferos tienen tres homólogos, Desert (DHH), Indian (IHH) y de Sonic (SHH). Estas proteínas cumplen múltiples funciones en el desarrollo embrionario, tales como desarrollo de miembros, tubo neural, cartílago, hueso, ovarios, testículo y formación de nervios perisféricos (Briscoe \& Thérond, 2013). Al analizar los receptores involucrados a la vía de señalización, además de la participación de los receptores patched, también los receptores smoothened juegan un papel fundamental en la activación de los factores de transcripción, debido a que la unión de la proteína $\mathrm{Hh}$ al receptor patched, provoca la fosforilación del receptor smoothened, generando la actividad celular mediante factores de transcripción (Fig. 1) (Choy \& Cheng, 2012).

Otro término es la Superfamilia del Factor de Crecimiento Epidérmico (Superfamilia factoris epidermalis [EGF] crescentiae), que se encuentra clasificado con acti- 

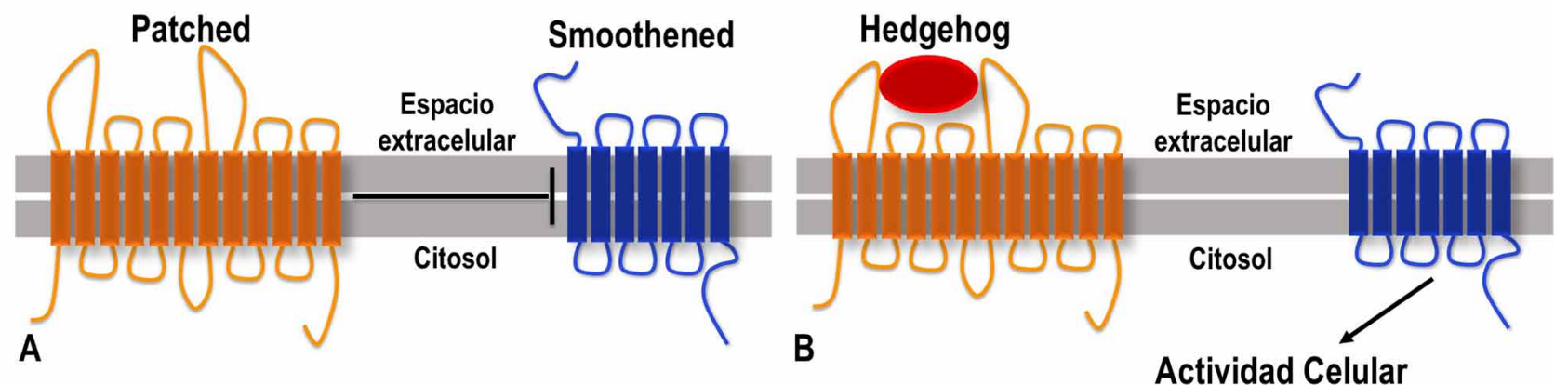

Fig. 1. Esquema del receptor patched y smoothened. En A, receptor patched inhibiendo la actividad de smoothened. En B, la unión de la proteína Hedgehod a patched, provocando la fosforilación de smoothened.

vidad asociada al receptor serina/treonina kinasa (Receptor serini/threonini kinasis). Este factor de crecimiento es esencial para el desarrollo de glándulas, como la glándula mamaria (Normanno et al., 2017). Su receptor se encuentra en la superficie celular y se activa mediante la unión de sus ligandos específicos, incluyendo el Factor de Crecimiento Epidérmico (EGF) y el Factor de Crecimiento Transformante alfa (TGF $\alpha$ ). Tras la activación del factor de crecimiento por sus ligandos, el receptor de EGF sufre una transición de una forma monomérica inactiva a una forma homodimérica activa (Holowka \& Baird, 2017). Además de la formación de homodímeros después de la unión del ligando, el receptor puede unirse a otro miembro de la familia de receptores, como el ErbB2/Her2/neu, para crear un heterodímero activado (Fig. 2). Todos estos receptores están asociados a tirosina kinasa, y no a serina/treonina kinasa (Reichelt et al., 2017).

En cuanto a los términos ligando fibronectina/ laminina (Ligantia fibronectini/laminini) y ligando delta/ serrate (Ligantia delta/serrata), asociados a los receptores integrina y notch, respectivamente (Receptor integrini, Receptor incisurans), no corresponden a proteínas o factores de crecimiento en específico. Un ligando es una molécula que forma un complejo con una biomolécula. En un sentido más estricto, es una molécula que envía una señal al unirse al centro activo de una proteína. En enzimas o proteínas no enzimáticas, especialmente de proteínas reguladoras o transportadoras, se denomina ligando a aquella molécula que se une al centro activo de la proteína para que ésta pueda realizar su función (transportar o inhibir una reacción metabólica) (Dong et al., 2017). En el caso del receptor integrina, corresponde a un heterodímero con dos subunidades, a y b, que se unen de forma no covalente a su ligando (Fig. 3). Son claves en el anclaje de la célula a la matriz extracelular, migración celular y transducción de señal (De Franceschi et al., 2015). Por otro lado, notch es un receptor transmembrana, el cual para tener un dominio extracelular requiere que posterior a su síntesis se produzca un primer clivaje en el aparato de Golgi por una proteasa. Tras la unión del ligando con el receptor, se produce endocitosis del complejo delta-notch o serrate-notch y el segundo clivaje por otra proteasa y se activa el receptor. Luego, se produce un tercer clivaje en la cola citoplasmática de notch por una proteasa intracelular. Esta cola clivada es capaz de viajar al núcleo, uniéndose a proteínas reguladoras de genes, interviniendo en procesos

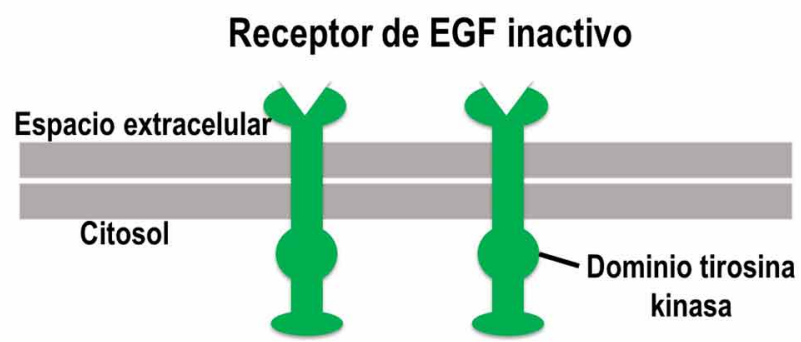

A

Fig. 2. Esquema del receptor del Factor de Crecimiento Epidermal (EGF). En A, la forma monomérica inactiva del receptor. En B, forma homodimérica activa del receptor unido a EGF, con actividad tirosina kinasa. 
como proliferación, crecimiento, diferenciación y apoptosis (Fig. 4) (Chillakuri et al., 2012).

La mayoría de los términos del ítem analizado no cumple con las recomendaciones hechas por $T E$ para su construcción, ya que no otorgan necesariamente un valor informativo ni funcional. De hecho, la mayoría de ellos son de amplio uso en genética y proteómica, donde la construcción de los términos es distinta. Esta es llevada a cabo por el Human Gene Nomenclature Committee (HGNC), perteneciente a la Human Genome Organisation (HUGO), quienes plantearon las directrices para la nomenclatura de los genes humanos en 1979, cuando se le dio por primera vez al HGNC la autoridad de aprobar y poner en práctica los nombres de genes humanos y los símbolos (Shows et al., 1980). Las actualizaciones de estas direc- trices se publicaron en 1987, 1995 y 1997. Con las recientes publicaciones de la secuencia completa del genoma humano hay un total estimado de 26.000 - 40.000 genes, como lo sugiere el Internacional Human Genome Sequencing Consortium (Yates et al., 2017). La filosofía del HGNC es que "La nomenclatura de genes debe evolucionar con la nueva tecnología en lugar de ser restrictiva como ocurre a veces cuando se aplican sistemas de nomenclatura de genes históricos e individuales". El principio fundamental de la nomenclatura es que cada nombre debe ser breve y lo más específico posible, además de expresar el carácter o función del gen, pero no deben intentar describir todo lo conocido sobre el tema. La primera letra del símbolo debe ser la misma que el nombre con el fin de facilitar la lista en orden alfabético y agrupación (Gray et al., 2016).
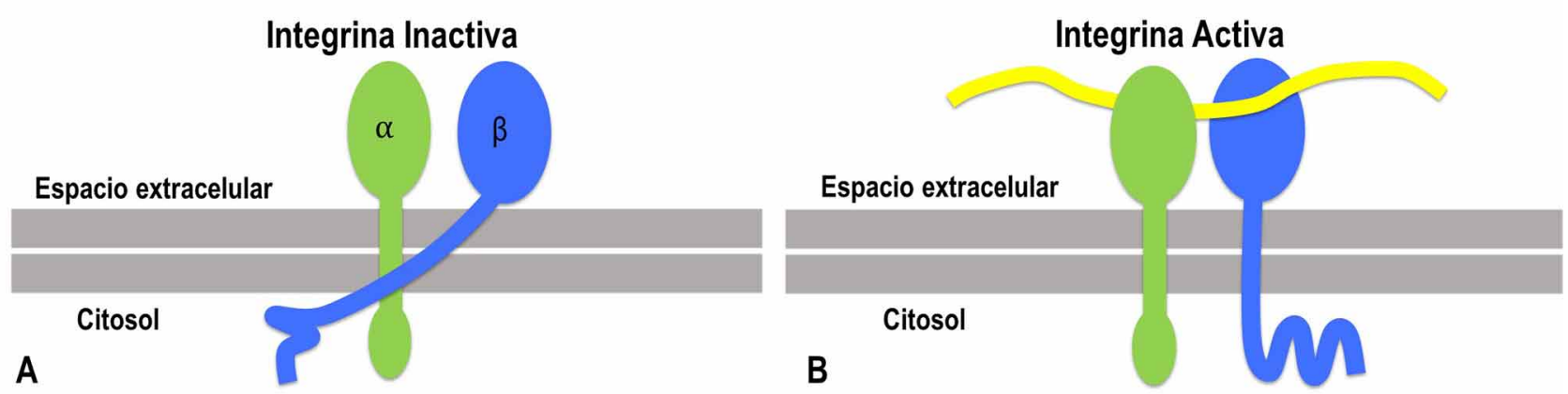

Fig. 3. Esquema del ligando fibronectina/laminina con el receptor integrina. En A, la forma inactiva del receptor con sus subunidades a y b. En B, la forma activa del receptor unido a su ligando.

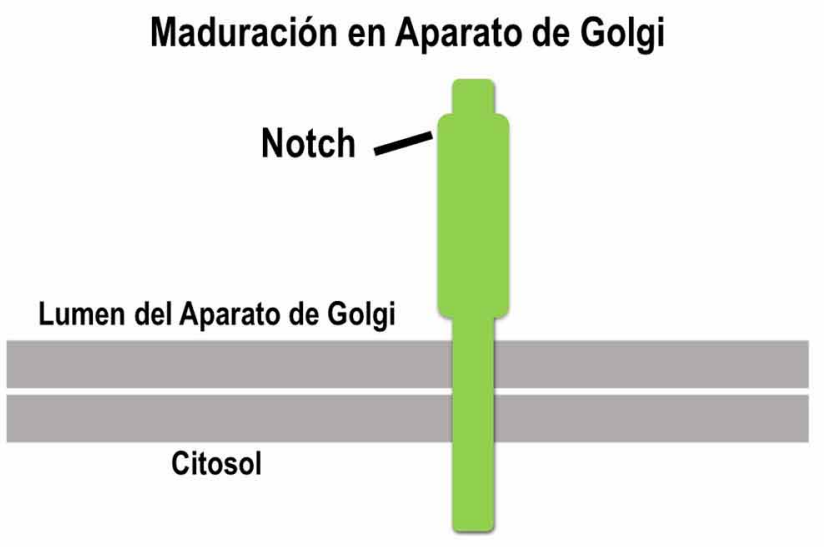

A

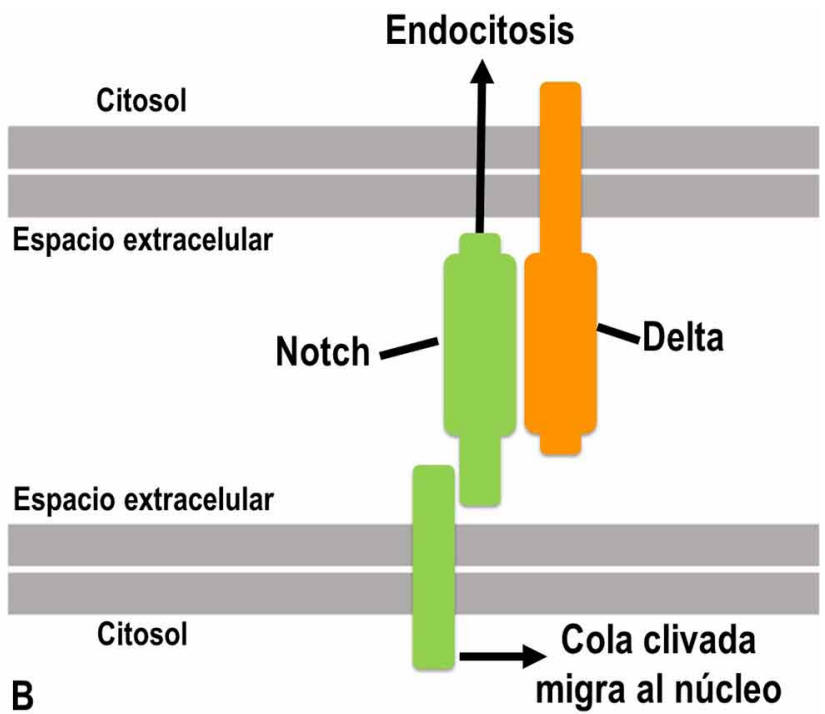

B migra al núcleo

Fig. 4. Esquema del ligando delta/serrate con el receptor notch. En A, primer clivaje de notch en el aparatode Golgi. En B, unión a delta genera endocitosis del fragmento delta-notch, y cola de notch migra al núcleo. 


\section{DISCUSIÓN}

Los términos agrupados en Terminologia Embryologica intentan dar una definición desde una perspectiva semántica a la estructura o proceso biológico en particular, intentando concordar con uno de los principios fundamentales para su construcción: poseer un valor informativo tanto de la función como de la morfología de la estructura. Sin embargo, se puede evidenciar que en algunas ocasiones esta condición no se cumple. También ocurre que la forma estructural y organizacional en la que se presentan los términos no es la más adecuada para su presentación, generando confusión.

Este es uno de los errores que se presenta en el ítem "Factores de crecimiento", ya que como se aprecia en el caso de la Familia Hedgehog y la Superfamilia del Factor de Crecimiento Epidérmico, no existe una concordancia entre las vías de señalización de cada uno de ellos con el tipo de receptor que se activa y con el cual han sido clasificados. Por ejemplo, en el caso de la Familia Hedgehog, no sólo los receptores patched se involucran en su activación, sino también los receptores smoothened. En el caso de la Superfamilia del Factor de Crecimiento Epidérmico, los receptores que se activan son asociados a tirosina kinasa y no a serina/treonina kinasa, como se encuentran clasificados.

Otro error visualizado es el caso de los ligandos fibronectina/laminina y delta/serrate, en donde por definición, no corresponden a factores de crecimiento sino a pequeñas moléculas que se pueden unir a los centros activos de ciertas proteínas y así realizar su función.

Esto claramente crea confusión, generando una visión alterada de la realidad morfológica, teniendo como consecuencia que estudiantes, profesionales, profesores e investigadores se desorienten (Duque et al., 2009).

Ahora bien, $T E$ hace una aclaración en el ítem analizado, dejando de manifiesto que se incluyen algunos factores de crecimiento involucrados en la embriogénesis normal y en el desarrollo de malformaciones congénitas, entendiendo además que en esta materia los avances científicos son dinámicos, descubriéndose día a día otros factores de crecimiento como también otras funciones que éstos puedan tener. Pero lo más importante, es que se abre a la discusión en cuanto a la inclusión de otros criterios a los propuestos por TE. Por ende, se necesita que en el ámbito iberolatinoamericano se haga un trabajo en conjunto entre distintos organismos encargados de analizar este tema, como lo son los Simposios
Iberolatinoamericanos de Terminología Anatómica, Histológica y Embriológica (SILAT), las sociedades científicas, universidades, entre otros, con el fin de lograr que la comunidad en su conjunto se haga partícipe. De esta manera, tendrá un impacto directo en el campo de la investigación, de la docencia y la ciencia en general, y así se facilitará el intercambio y el avance científico en IberoLatinoamérica (Losardo et al.).

Se espera que en un futuro cercano y con más antecedentes se puedan unificar criterios, ya sea en los Comités de Terminologías de los diferentes países, como también en los SILAT y que estas recomendaciones puedan ser finalmente consideradas por los expertos que conforman la FIPAT, en beneficio de la comunidad científica internacional y especialmente para aquellos que se dedican a la enseñanza de las diferentes áreas de las ciencias morfológicas del área de la medicina (Vásquez \& del Sol, 2015).

CONEI, D. \& ROJAS, M. Growth factors included in Terminologia Embryologica: Critical analysis. Int. J. Morphol., 36(2):500-506, 2018.

SUMMARY: Each term included in Terminologia Embryologica (TE), published in 2013 and with a second edition in 2017 subject to approval by the Federative International Programme For Anatomical Terminology (FIPAT), must be structured based on its principles: Names must have an informative value, eponyms, homonyms and concordant names are deleted. However, this does not happen in some terms. That is why the terms included in the section "Growth Factors" (Factores crescentiae, E.4.0.1.0.0.0.1) were analyzed in the way they are presented, their concordance with what was published in reviews of PubMed database, and their naming form was described based on what was used by the Genes Nomenclature Committee of the Human Genome Organisation (HGNC). It was evidenced that in the terms Family Hedgehog (Familia erinacea, E.4.0.1.0.0.0.6) and Superfamily of the Epidermal Growth Factor (EGF) (Superfamilia factoris epidermalis [EGF] crescentiae, E.4.0.1.0.0.0.10) these do not agree with the classification proposed by $T E$ based on the receiver that is involved in the activity of the growth factor, since in the case of Hedgehog family not only does the patched receptor participate, but the smoothened one does as well. In EGF there is tyrosine kinase receptor activity and not serine/threonine kinase, as presented in the official document. Also, the ligands fibronectin/laminin and delta/serrate appear as growth factors, despite not being catalogued as such. Furthermore, oftentimes the way in which such terms are constructed is contrary to the FIPAT presentation, but follows the HGNC line of work that holds the HGNC.

KEY WORDS: Terminologia Embryologica; Growth Factors; Hedgehog Family; Epidermal Growth Factor Superfamily; Ligand; HUGO Gene Nomenclature Committee. 


\section{REFERENCIAS BIBLIOGRÁFICAS}

Briscoe, J. \& Thérond, P. P. The mechanisms of Hedgehog signalling and its roles in development and disease. Nat. Rev. Mol. Cell Biol., 14(7):416-29, 2013.

Chillakuri, C. R.; Sheppard, D.; Lea, S. M. \& Handford, P. A. Notch receptor-ligand binding and activation: insights from molecular studies. Semin. Cell Dev. Biol., 23(4):421-8, 2012.

Choy, S. W. \& Cheng, S. H. Hedgehog signaling. Vitam. Horm., 88:1-23, 2012.

De Franceschi, N.; Hamidi, H.; Alanko, J.; Sahgal, P. \& Ivaska, J. Integrin traffic - the update. J. Cell Sci., 128(5):839-52, 2015.

Dong, Y.; Sun, Q. \& Zhang, X. PD-1 and its ligands are important immune checkpoints in cancer. Oncotarget, 8(2):2171-86, 2017.

Duque, P. J. E.; Moscoso, A. O. \& Morales, P. G. Consideraciones nominales anátomo-funcionales sobre el lobo prefrontal. Arch. Anat. Costa Rica, 4:43, 2009.

Federative International Programme for Anatomical Terminology (FIPAT). Terminologia Embryologica. Fribourg, International Federation of Associations of Anatomists, University of Fribourg, 2009. Disponible en: http://www.unifr.ch/ifaa/Public/EntryPage/ViewSource.html

Federative International Programme for Anatomical Terminology (FIPAT). History of International Anatomical Terminology. In: International Federation of Associations of Anatomists (IFAA). IFAA documentation: FICAT History. Fribourg, International Federation of Associations of Anatomists, University of Fribourg, 2010. Disponible en: http:// www.unifr.ch/ifaa/Public/EntryPage/PDF/History\%20FICAT.pdf

Federative International Programme for Anatomical Terminology (FIPAT). Terminologia Embryologica. International Embryological Terminology. Stuttgart, Thieme, 2013.

Federative International Programme for Anatomical Terminology (FIPAT). Terminologia Embryologica. International Embryological Terminology. $2^{\mathrm{a}}$ ed. Federative International Programme for Anatomical Terminology, 2017. Disponible en: http://fipat.library.dal.ca/TE2/

Gray, K. A.; Seal, R. L.; Tweedie, S.; Wright, M. W. \& Bruford, E. A. A review of the new HGNC gene family resource. Hum. Genom., 10:6, 2016.

Holowka, D. \& Baird, B. Mechanisms of epidermal growth factor receptor signaling as characterized by patterned ligand activation and mutational analysis. Biochim. Biophys. Acta, 859(9 Pt. A):1430-5, 2017.

HUGO Gene Nomenclature Committee (HGNC). Gene Families Index. Hinxton, HUGO Gene Nomenclature Committee, 2017. Disponible en: http://www.genenames.org/cgi-bin/genefamilies/

Latarjet, M. \& Ruiz Liard, A. Anatomía Humana. $4^{a}$ ed. Madrid, Médica Panamericana, 2004.

Li, J. \& Dong, S. The signaling pathways involved in chondrocyte differentiation and hypertrophic differentiation. Stem Cells Int., 2016:2470351, 2016.

Losardo, R. J.; Barbato de Prates, N. E. V.; Arteaga-Martínez, M.; Cabral, R. H. \& García-Peláez, M. I. International Morphological Terminology: More than anatomy, histology and embryology. Int. J. Morphol., 33(1):400-7, 2015.

Normanno, N.; Denis, M. G.; Thress, K. S.; Ratcliffe, M. \& Reck, M. Guide to detecting epidermal growth factor receptor (EGFR) mutations in ctDNA of patients with advanced non-small-cell lung cancer. Oncotarget, 8(7):12501-6, 2017.

Reichelt, M. E.; O'Brien, S.; Thomas, W. G. \& Headrick, J. P. Transactivation of the epidermal growth factor receptor in responses to myocardial stress and cardioprotection. Int. J. Biochem. Cell Biol., 83:97-110, 2017.

Shows, T. B.; Alper, C. A.; Bootsma, D.; Dorf, M.; Douglas, T.; Huisman, T.; Kit, S.; Klinger, H. P.; Kozak, C.; Lalley, P. A.; Lindsley, D.; McAlpine, P. J.; McDougall, J. K.; Meera Khan, P.; Meisler, M.; Morton, N. E.; Opitz, J. M.; Partridge, C. W.; Payne, R.; Roderick, T. H.; Rubinstein, P.; Ruddle, F. H.; Shaw, M.; Spranger, J. W. \& Weiss, K.
International System for Human Gene Nomenclature (1979) ISGN (1979). Birth Defects Orig. Artic. Ser., 15(11):96-116, 1980.

Vásquez, B. \& del Sol, M. Terminologia Anatomica and Terminologia Histologica. A meeting point between morphologists. Int. J. Morphol., 33(4):1585-90, 2015.

Vásquez, B. \& del Sol, M. The Terminologia Histologica in the medical sciences. Int. J. Morphol., 32(1):375-80, 2014.

Wang, Y.; Lu. P.; Zhao, D. \& Sheng, J. Targeting the hedgehog signaling pathway for cardiac repair and regeneration. Herz, 42(7):662-8, 2017.

Yates, B.; Braschi, B.; Gray, K. A.; Seal, R. L.; Tweedie, S. \& Bruford, E. A. Genenames.org: the HGNC and VGNC resources in 2017. Nucleic Acids Res., 45(D1):D619-D625, 2017.

\author{
Dirección de Correspondencia: \\ Daniel Conei Valencia \\ Departamento de Ciencias Morfológicas \\ Facultad de Ciencia \\ Universidad San Sebastián \\ Puerto Montt \\ CHILE
}

Email: dconeiv@docente.uss.cl

Recibido : 15-01-2018

Aceptado: 10-02-2018 